СРАВНИТЕЛЬНАЯ ХАРАКТЕРИСТИКА ВОЗРАСТНЫХ, ПОЛОВЫХ И ТИПОВЫХ МОРФОМЕТРИЧЕСКИХ ПАРАМЕТРОВ НЕПАРНЫХ ВЕТВЕЙ БРЮШНОЙ АОРТЫ ВЗРОСЛОГО ЧЕЛОВЕКА ПО ДАННЫМ КОМПЬЮТЕРНОЙ ТОМОГРАФИИ

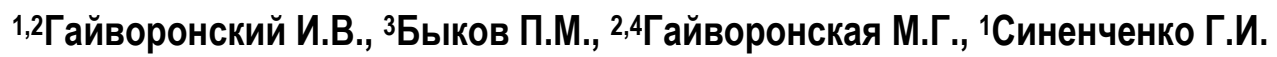

${ }^{1}$ Военно-медицинская академия имени С.М. Кирова, Санкт-Петербург, Россия; ${ }^{2}$ Санкт-Петербургский государственный университет, СанктПетербург, Россия; ${ }^{3}$ Белгородский государственный национальный исследовательский университет, Белгород, Россия; ${ }^{4}$ Национальный медицинский исследовательский центр имени В.А. Алмазова, Санкт-Петербург, Россия, e-mail: i.v.gaivoronsky@mail.ru

\title{
THE COMPARATIVE CHARACTERISTICS OF AGE, SEXUAL AND TYPOLOGICAL MORPHOMETRIC PARAMETERS OF UNPAIRED BRANCHES OF THE ABDOMINAL AORTA OF ADULTS ACCORDING COMPUTED TOMOGRAPHY \\ 1,2Gaiyvoronsky IV, 3Bykov PM, 2,4Gaivoronskaya MG, ${ }^{1}$ Sinenchenko GI \\ ${ }^{1}$ Kirov Military Medical Academy, Saint-Petersburg, Russia; ${ }^{2}$ Saint-Petersburg State University, Saint-Petersburg, Russia; ${ }^{3 B}$ Belgorod State National Research University, Belgorod, Russia; ${ }^{4}$ Almazov National Medical Research Center, Saint-Petersburg, Russia, e-mail: i.v.gaivoronsky@mail.ru
}

\section{Дия циитирования:}

Гайворонский И.В., Быков П.М., Гайворонская М.Г., Синенченко Г.И. Сравнительная характеристика возрастных, половых и типовых морфометрических параметров непарных ветвей брюшной аорты взрослого человека// Морфологические ведомости.- 2019.- Том 27.- № 2.C. 13-18. https://doi.org/10.20340/mv-mn.19(27).02.13-18

For the citation:

Gaivoronsky IV, Bykov PM, Gaivoronskaya MG, Sinenchenko GI. The comparative characteristics of age, sexual and typological morphometric parameters of unpaired branches of the abdominal aorta of adults according computed tomography. Morfologicheskie Vedomosti - Morphological Newsletter. 2019 August 5;27(2):13-18. https://doi.org/10.20340/mv-mn.19(27).02.13-18

Резюме: Стремительное развитие трансплантологии, эндоваскулярной и мини-инвазивной хирургии обуславливают необходимость детального изучения особенностей строения сосудов брюшной полости. Цель исследования - изучение особенностей морфометрических параметров брюшной аорты и ее непарных ветвей у мужчин и женщин в различные возрастные периоды в зависимости от типа телосложения. Проведен анализ 266 компьютерных томограмм брюшной части аорты и ее непарных ветвей у взрослых мужчин и женщин, разделенных на три возрастные группы (первый и второй периоды зрелого возраста и пожилой возраст), а также на три группы согласно индексу Пинье (астенический, нормостенический и гиперстенический типы телосложения). Установлено, что отдельные морфометрические параметры брюшной части аорты и ее непарных ветвей у мужчин и женщин существенно изменяются с возрастом. Доказано, что диаметр аорты на различных уровнях достоверно увеличивается с возрастом от первого зрелого возраста к пожилому в среднем на 5 мм. При этом у мужчин длина брюшного отдела аорты, чревного ствола и основного ствола верхней брыжеечной артерии с возрастом не изменяются. У женщин длина чревного ствола с возрастом увеличивается на 5,9 мм, длина основного ствола верхней брыжеечной артерии - на 17 мм. Угол отхождения чревного ствола у мужчин с возрастом изменяется неравномерно, во втором периоде зрелого возраста происходит его статистически достоверное уменьшение в среднем на $12,3^{\circ}$, затем в пожилом возрасте - увеличение на $15^{\circ}$. При этом у женщин значения данного показателя изменяются более равномерно. Углы отхождения других сосудов четкой возрастной зависимости не показали, поскольку данный параметр в большей степени обусловлен конституциональными особенностями. Аорто-мезентериальное расстояние с возрастом изменяется только у женщин. В пожилом возрасте оно в среднем на 4,4 мм больше, чем в первом периоде зрелого возраста. Также установлено, что между конституциональными типами, выделенными с использованием индекса Пинье, имеются достоверные различия по подавляющему большинству из изученных морфометрических параметров. Полученные сведения имеют важное клиническое значение, поскольку позволят объективизировать диагностические критерии различных сосудистых синдромов и минимизировать риск проводимых рентгеноэндоваскулярных вмешательств.

Ключевые слова: брюшная аорта, пол, возраст, тип телосложения, компьютерная томография

Summary: The rapid development of transplantation, endovascular and minimally invasive surgery necessitates a detailed study of the structural features of the vessels of the abdominal cavity. The purpose of the study is the characteristics of the morphometric parameters of the abdominal aorta and its unpaired branches in men and women at different ages and depending on the body type. The analysis of 266 computer tomograms of the abdominal part of aorta and its unpaired branches was carried out in adult men women divided into three age groups (first and second periods of mature age and elderly age), as well as into three groups according to the Pinier index (asthenic, normosthenic and hypersthenic body types). It was established that individual morphometric parameters of the abdominal part of aorta and its unpaired branches in men and women significantly change with age. It is proved that the diameter of the aorta at various levels significantly increases with age from the first mature to the elderly age by an average of $5 \mathrm{~mm}$. However, in men, the length of the abdominal aorta, celiac trunk and main trunk of the superior mesenteric artery does not change with age. In women, the length of the celiac trunk increases with age at $5.9 \mathrm{~mm}$, the length of the main trunk of the superior mesenteric artery - at $17 \mathrm{~mm}$. The angle of discharge of the celiac trunk in men changes unevenly with age - in the second period of mature age, there is a statistically significant decrease by an average to $12.3^{\circ}$, then in old age an increase to $15^{\circ}$. Moreover, in women, the values of this indicator vary more evenly. The angles of discharge of other vessels did not show a clear age dependence, since this parameter is largely due to the constitutional features. The aorto-mesenteric distance changes with age only in women. In elderly age, it is on average $4.4 \mathrm{~mm}$ larger than in the first period of mature age. It was also found that there are significant differences between constitutional types identified using the Pinier index in the overwhelming majority of the morphometric parameters studied. The obtained information has a significant clinical importance, since it will allow objectifying the diagnostic criteria of various vascular syndromes and minimizing the risk of endovascular interventions.

Key words: abdominal aorta, sex, age, body type, computed tomography

Введение. Брюшная аорта является основным источником кровоснабжения органов брюшной полости и забрюшинного пространства и располагается на передней поверхности позвоночника несколько левее срединной плоскости [1-4]. Наиболее часто бифруркация аорты располагается на уровне IV поясничного позвонка, в 15\% случаев - на уровне 
межпозвонкового диска между IV и V позвонками и в 15\% случаев - на уровне V позвонка [5]. Непарными ветвями брюшной части аорты являются: чревный ствол, верхняя (далее - ВБА) и нижняя (далее - НБА) брыжеечные артерии. Устье чревного ствола располагается на уровне нижнего края XII грудного позвонка, что совпадает примерно с верхним краем поджелудочной железы [6-7]. Описаны случаи его отхождения на уровне верхнего края I поясничного позвонка [8]. ВБА отходит от передней стенки аорты, либо незначительно отклоняется к ее правой или левой стенке. Уровень отхождения ВБА может находиться на уровне от XII грудного позвонка до межпозвоночного диска между I-II поясничными позвонками [5]. НБА отходит от дистального отдела аорты на уровне II-IV поясничных позвонков [6]. По данным некоторых авторов, НБА отходит от нижнего края III поясничного позвонка [2]. Sinkeet et al. (2013) указывают на то, что в 91,4\% случаев она начинается между $L_{2}$-L4 позвонками [9]. В литературе сведения о возрастных, половых и типовых особенностях морфометрических параметров брюшной части аорты и ее непарных ветвей представлены недостаточно подробно. Стремительное развитие трансплантологии, эндоваскулярной и мини-инвазивной хирургии обуславливают возросший интерес к этой проблеме [10-12].

Цель исследования - изучить по данным компьютерной томографии особенности морфометрических параметров брюшной аорты и ее непарных ветвей у мужчин и женщин в различные возрастные периоды и в зависимости от типа телосложения.

Материалы и методы исследования. Объект исследования - компьютерные томограммы. В исследовании использованы компьютерные томограммы брюшного отдела аорты в случаях без обнаружения сосудистой и иной патологии у пациентов, которым компьютерная томография была произведена по соответствующим диагностическим показаниям. Мультисрезовая спиральная компьютерная томография была проведена на компьютерном томографре «Aquilion 64» фрирмы «Toshiba» (Япония). Внутривенное контрастирование осуществлялось с помощью автоматического шприца-инжектора путем введения йодсодержащего контрастного препарата с концентрацией йода 370 мг/мл со скоростью введения 4,5 мл/с. Процедура сканирования проводилась по стандартной методике, в том числе, в артериальную фразу контрастирования (через 5 секунд после достижения пиковой концентрации контрастного вещества в аорте на уровне диафрагмы). Толщина реконструктивного среза получаемых изображений составляла 0,5 мм. Анализ полученных данных осуществлялся на индивидуальной компьютерной рабочей станции врача-рентгенолога «Vitrea 4.3» с использованием специализированного программного пакета для изучения сосудистой системы (Vascular: Aorta CT).

Проведен анализ морфометрических показателей брюшной части аорты и ее непарных ветвей взрослых людей, относящихся к разным возрастным группам согласно классификации Маркосяна [13]. Случаи томографии были распределены на три возрастные группы: I - 1-й период зрелого возраста (38 мужчин и 28 женщин); II - 2-й период зрелого возраста (40 мужчин, 36 женщин); III - пожилой возраст (36 мужчин и 88 женщин). Для определения типа телосложения использовался индекс Пинье, определяющийся по формуле Индекс Пинье=Р-(М+ОГК), в котоой Р - рост человека, М - масса тела; ОГК объем грудной клетки в покое. Черноруцкий (1929) величины этого индекса использовал для определения типа конституции. Согласно его классификации, у нормостеников индекс Пинье равен 10-30, астеников - больше 30, гиперстеников - меньше 10. Согласно значению индекса Пинье, выделено три группы наблюдаемых случаев: I группа - астенический; II нормостенический; III - гиперстенический типы телосложения. Морфометрические данные (длина сосудов, углы их отхождения, диаметр и другие) получали в наиболее репрезентативных для каждого параметра проекциях (двухмерной, криволинейной, мультипланарной, проекции максимальной интенсивности, объемном рендеринге). Статистическая обработка полученных данных осуществлялась с использованием пакета прикладных программ Statistica 7.0. Для каждого признака определялись: среднее арифметическое значение, ошибка среднего арифметического. Для выявления значимости различия между средними величинами определялся t-критерий Стьюдента.

Результаты исследования и обсуждение. Установлено, что отдельные морфометрические параметры брюшной части аорты и ее непарных ветвей существенно изменяются с возрастом и у мужчин, и у женщин (таблица 1). Диаметр аорты на уровне чревного ствола (далее - ЧС) с возрастом статистически достоверно увеличивается и у мужчин, и у женщин в среднем на 5 мм $(p<0,05)$. Диаметр данного сосуда на других уровнях (на уровне 5 мм проксимальнее устьев почечных артерий и на уровне 5 мм проксимальнее бифуркации) также достигает наибольших значений в пожилом возрасте, увеличиваясь у мужчин в среднем на 4,6 и 3,3 мм, у женщин - на 3,0 и 3,4 мм, соответственно. Относительный прирост диаметра данного сосуда на уровне чревного ствола с возрастом составляет у мужчин 24,5\%, у женщин - 26,7\%; на уровне 5 мм проксимальнее устьев почечных артерий у мужчин - 24,9\%, у женщин - 19,7\%; на уровне 5 мм проксимальнее бифуркации аорты - 20,6\% и 25,2\%, соответственно.

Изменения диаметра чревного ствола и его ветвей (левой желудочной и селезеночной артерий) с возрастом происходят не столь значительно и протекают по разному в зависимости от пола. У мужчин пожилого возраста наибольший диаметр чревного ствола на 0,9 мм (10,9\%) меньше, чем у мужчин первого периода зрелого возраста. У женщин возрастные изменения данного параметра выражены слабо. Диаметр левой желудочной и селезеночной артерии у мужчин также достоверно уменьшается с возрастом в среднем на 10,5 и 6,9\%, соответственно. У женщин диаметр левой желудочной артерии не имеет статистически достоверных различий между группами, а диаметр селезеночной артерии увеличивается с возрастом на 7\%. Диаметр общей печеночной артерии, а также диаметр ВБА и НБА с возрастом не изменяются ни у мужчин, ни у женщин.

Установлено, что у мужчин длина брюшного отдела аорты, чревного ствола и длина основного ствола ВБА с возрастом верно не изменяются ( $p<0,05)$, при этом у женщин длина чревного ствола с возрастом увеличивается на 5,9 мм, длина основного ствола ВБА - на 17 мм. Таким образом, у женщин относительный прирост длины чревного ствола с возрастом составляет 26,9\%, длины основного ствола ВБА - 9,1\%. Длина основного ствола НБА у мужчин и женщин с возрастом изменяется не одинаково. У женщин достоверные различия по данному показателю имеются только между группами 1-го периода зрелого возраста и пожилого возраста, у мужчин между группами 1-го и 2-го периодов зрелого возраста. Относительный прирост диаметра данного сосуда с возрастом у женщин составляет 13,5\%, у мужчин - 8,1\%. 
Таблица 1

Сравнительные значения морфометрических параметров брюшной части аорты и ее непарных ветвей

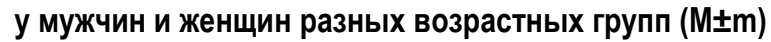

\begin{tabular}{|c|c|c|c|c|}
\hline \multirow[b]{2}{*}{ Морфомметрический параметр } & \multirow[b]{2}{*}{ Пол } & \multicolumn{3}{|c|}{ Возрастные группы } \\
\hline & & $\begin{array}{c}\text { 1-й период } \\
\text { зрелого возраста }\end{array}$ & $\begin{array}{c}\text { 2-й период } \\
\text { зрелого возраста }\end{array}$ & $\begin{array}{c}\text { Пожилой } \\
\text { возраст }\end{array}$ \\
\hline \multirow{2}{*}{ Диаметр аорты на уровне чревного ствола, мм } & M & $20,4 \pm 0,6^{2,3}$ & $24,2 \pm 0,2^{1,3}$ & $25,4 \pm 0,2^{1,2}$ \\
\hline & ж & $18,3 \pm 0,4^{2,3}$ & $20,6 \pm 0,3^{1,3}$ & $23,2 \pm 0,41,2$ \\
\hline \multirow{2}{*}{$\begin{array}{c}\text { Поперечный диаметр аорты на уровне } 5 \text { мм } \\
\text { проксимальнее устьев почечных артерий (либо устья } \\
\text { проксимальнее распложенной почечной артерии), мм }\end{array}$} & M & $18,5 \pm 0,4^{2,3}$ & $22,0 \pm 0,3$ & $23,1 \pm 0,7^{1,2}$ \\
\hline & Ж & $16,3 \pm 0,4^{2,3}$ & $17,7 \pm 0,2^{1,3}$ & $20,3 \pm 0,2^{1,2}$ \\
\hline \multirow{2}{*}{$\begin{array}{c}\text { Поперечный диаметр аорты на уровне } 5 \text { мм } \\
\text { проксимальнее бифруркации аорты, мм } \\
\end{array}$} & M & $16,0 \pm 0,4^{2,3}$ & $18,9 \pm 0,3$ & $19,3 \pm 0,2^{1,2}$ \\
\hline & ж & $13,5 \pm 0,3^{2,3}$ & $14,6 \pm 0,11,3$ & $16,9 \pm 0,2^{1,2}$ \\
\hline \multirow{2}{*}{ Длина брюшного отдела аорты, мм } & $\mathrm{M}$ & $152,6 \pm 2,7$ & $153,4 \pm 2,3$ & $152,2 \pm 1,9$ \\
\hline & Ж & $145,0 \pm 2,1$ & $145,0 \pm 2,4$ & $150,0 \pm 1,6$ \\
\hline \multirow{2}{*}{ Длина чревного ствола, мм } & $\mathrm{M}$ & $24,7 \pm 1,1$ & $26,8 \pm 0,7$ & $27,4 \pm 0,8$ \\
\hline & Ж & $21,9 \pm 0,8^{3}$ & $23,1 \pm 0,91,3$ & $27,8 \pm 0,6^{1,2}$ \\
\hline \multirow{2}{*}{ Наибольший диаметр чревного ствола, мм } & $\mathrm{M}$ & $8,2 \pm 0,2^{3}$ & $8,7 \pm 0,2$ & $7,3 \pm 0,2^{2}$ \\
\hline & Ж & $7,2 \pm 0,2$ & $7,2 \pm, 02$ & $7,4 \pm 0,1$ \\
\hline \multirow{2}{*}{ Угол отхождения чревного ствола в градусах } & M & $38,1 \pm 2,7^{2}$ & $25,8 \pm 2,71,3$ & $40,8 \pm 2,4^{2}$ \\
\hline & ж & $32,5 \pm 2,5^{3}$ & $39,6 \pm 2,9$ & $42,3 \pm 2,11,2$ \\
\hline \multirow{2}{*}{ Диаметр левой желудочной артерии, мм } & $\mathrm{M}$ & $3,8 \pm 0,1$ & $3,8 \pm 0,1$ & $3,4 \pm 0,1$ \\
\hline & Ж & $3,08 \pm 0,1$ & $3,2 \pm 0,1$ & $3,0 \pm 0,1$ \\
\hline \multirow{2}{*}{ Диаметр селезеночной артерии, мм } & M & $6,5 \pm 0,2$ & $6,6 \pm 0,1$ & $5,9 \pm 0,2$ \\
\hline & Ж & $5,8 \pm 0,2$ & $5,8 \pm 0,1$ & $6,2 \pm 0,1$ \\
\hline \multirow{2}{*}{ Диаметр общей печеночной артерии, мм } & M & $5,8 \pm 0,2$ & $6,0 \pm 0,2$ & $5,4 \pm 0,2$ \\
\hline & Ж & $5,6 \pm 0,2$ & $5,1 \pm 0,1$ & $5,3 \pm 0,1$ \\
\hline \multirow{2}{*}{$\begin{array}{c}\text { Расстояние между центрами устьев чревного ствола и } \\
\text { верхней брыжеечной артерии, мм }\end{array}$} & M & $19,3 \pm 0,4$ & $18,6 \pm 0,5$ & $18,7 \pm 0,4$ \\
\hline & ж & $17,0 \pm 0,9$ & $17,2 \pm 0,6$ & $17,9 \pm 0,4$ \\
\hline \multirow{2}{*}{ Длина основного ствола ВБА, мм } & $\mathrm{M}$ & $207,0 \pm 2,5$ & $205,0 \pm 4,0$ & $202,0 \pm 3,1$ \\
\hline & Ж & $184,0 \pm 4,1^{3}$ & $183,0 \pm 3,9^{3}$ & $201,0 \pm 2,6^{1,2}$ \\
\hline \multirow{2}{*}{ Наибольший диаметр ВБА (начальные отделы), мм } & M & $8,0 \pm 0,2$ & $8,2 \pm 0,2$ & $7,9 \pm 0,2$ \\
\hline & Ж & $6,7 \pm 0,2$ & $6,1 \pm 0,1$ & $6,9 \pm 0,1$ \\
\hline \multirow{2}{*}{$\begin{array}{l}\text { Диаметр ВБА на уровне } 5 \text { мм дистальнее устья } \\
\text { подвздошно-ободочно-кишечной артерии, мм }\end{array}$} & M & $5,1 \pm 0,1$ & $5,3 \pm 0,2$ & $5,2 \pm 0,1$ \\
\hline & ж & $4,1 \pm 0,2$ & $3,8 \pm 0,1$ & $4,5 \pm 0,1$ \\
\hline \multirow{2}{*}{ Угол отхождения ВБА в градусах } & $\mathrm{M}$ & $52,0 \pm 3,5$ & $61,0 \pm 3,1$ & $56,0 \pm 4,1$ \\
\hline & Ж & $39,4 \pm 3,9$ & $41,3 \pm 4,3$ & $47,5 \pm 2,0$ \\
\hline \multirow{2}{*}{ Аорто-мезентериальное расстояние, мм } & M & $17,1 \pm 1,2$ & $17,8 \pm 1,1$ & $15,6 \pm 1,3$ \\
\hline & Ж & $8,9 \pm 0,7^{3}$ & $11,0 \pm 1,1$ & $13,3 \pm 0,7^{1}$ \\
\hline \multirow{2}{*}{$\begin{array}{c}\text { Расстояние между центрами устьев верхней брыжеечной и } \\
\text { проксимальнее распложенной почечной артерии, мм }\end{array}$} & M & $11,1 \pm 1,2$ & $8,5 \pm 0,9^{3}$ & $12,1 \pm 1,1$ \\
\hline & Ж & $11,7 \pm 1,7$ & $9,9 \pm 1,1$ & $9,7 \pm 0,7$ \\
\hline \multirow{2}{*}{$\begin{array}{c}\text { Расстояние между центрами устьев верхней и нижней } \\
\text { брыжеечных артерий, мм }\end{array}$} & M & $76,0 \pm 2,2$ & $74,4 \pm 1,9$ & $77,3 \pm 1,6$ \\
\hline & Ж & $74,6 \pm 1,4$ & $72,2 \pm 2,2$ & $74,6 \pm 1,1$ \\
\hline \multirow{2}{*}{ Длина основного ствола НБА, мМ } & $\mathrm{M}$ & $54,3 \pm 2,02$ & $62,3 \pm 3,0$ & $58,7 \pm 3,4$ \\
\hline & Ж & $51,1 \pm 2,2$ & $55,4 \pm 2,3$ & $58,0 \pm 1,8$ \\
\hline \multirow{2}{*}{ Наибольший диаметр НБА (начальные отделы), мМ } & M & $4,4 \pm 0,1$ & $4,4 \pm 0,1$ & $4,1 \pm 0,2$ \\
\hline & Ж & $3,7 \pm 0,2$ & $3,5 \pm 0,1$ & $3,8 \pm 0,1$ \\
\hline \multirow{2}{*}{$\begin{array}{c}\text { Расстояние между центрами устьев нижней брыжеечной и } \\
\text { дистальнее распложенной почечной артерии, мм }\end{array}$} & M & $62,5 \pm 2,0$ & $60,1 \pm 2,0$ & $58,9 \pm 1,4$ \\
\hline & Ж & $56,8 \pm 1,6$ & $55,5 \pm 1,7^{3}$ & $60,2 \pm 1,0$ \\
\hline Расстояние между центром устья нижней брыжеечной & M & $41,8 \pm 1,8$ & $44,0 \pm 1,5$ & $41,7 \pm 1,6$ \\
\hline артерии и бифуркацией аорты, мм & Ж & $37,9 \pm 1,5$ & $40,7 \pm 1,5$ & $41,2 \pm 1,0$ \\
\hline
\end{tabular}

Примечание: М - мужчины; $Ж$ - женщины; ${ }^{1}$ - различия с группой 1-го периода зрелого возраста; ${ }^{2}$ - различия с группой 2-го периода зрелого возраста; ${ }^{3}$ - различия с группой пожилого возраста, $p<0,05$.

Наряду с вышеперечисленным отмечается возрастное изменение еще двух параметров: угла отхождения чревного ствола и аорто-мезентериального расстояния (наибольшее расстояние между указанными сосудами на уровне 
горизонтальной части двенадцатиперстной кишки). У мужчин угол отхождения чревного ствола с возрастом меняется неравномерно: сначала во 2-м периоде зрелого возраста происходит его достоверное уменьшение в среднем на $12,3^{\circ}$ $(32,3 \%)$, затем в пожилом возрасте - увеличение на $15^{\circ}(58,1 \%)$. У женщин значения данного показателя изменяются более равномерно, и достоверные различия имеются только между группами 1-го периода зрелого возраста и пожилого возраста и составляют 9,8 (относительный прирост 30,2\%). Аорто-мезентериальное расстояние с возрастом изменяется только у женщин: в пожилом возрасте оно на 4,4 мм (49,4\%) больше, чем в первом периоде зрелого возраста. Углы отхождения других сосудов четкой возрастной зависимости не показали, поскольку данный параметр в большей степени обусловлен конституциональными особенностями [13]. Таким образом, ряд морфометрических показателей брюшной части аорты и ее непарных ветвей с возрастом статистически значимо изменяется.

Возрастное увеличение диаметра аорты и отсутствие аналогичных изменений со стороны других сосудов может быть объяснено тем, что аорта является единственным из изученных сосудов, относящихся к артериям эластического типа. По данным Барсукова [14], у артерий эластического типа с возрастом нарастает атрофия эластического каркаса стенок с ее параллельной коллагенизацией, что приводит к постепенной дилятации сосуда вследствие низкой способности коллагеновых волокон сокращаться после растяжения, что и приводит к увеличению их диаметра. У артерий мышечно-эластического и мышечного типов такая тенденция может прослеживаться неотчетливо, либо быть обратной [15].

Как отмечают Жирнова и др. [16], удлинение сосудов с возрастом может быть связано с тем, что по мере старения артерии во внутренней ее оболочке дифффзно накапливаются гладкомышечные клетки, и разрастается соединительная ткань. Это приводит к утолщению, прежде всего, интимы. Также отмечается накопление отдельных липидов (ссрингомиелина и холестерола-линолеата). С функциональной точки зрения, эти возрастные изменения приводят к постепенному снижению эластичности и повышению ригидности сосудов. Артерии при этом становятся извитыми, могут расширяться и удлиняться. Выраженность внешнего поддерживающего каркаса внеорганных артерий тоже определяет способность сосудов противостоять кровяному давлению. Стенки непарных ветвей брюшной аорты имеют сниженную эластичность. Такой механизм изменений имеет наибольшее значение при артериальной гипертензии. По всей видимости, удлинение сосудов в нашей выборке объясняется именно этими факторами.

В литературе отсутствуют четкие мнения относительно того, почему возрастные изменения сосудов у женщин более выражены, чем у мужчин. Как отмечают Scuteri et al. [17], у женщин в постменопаузальный период либо после хирургической и(или) химической кастрации наблюдается прогрессирование изменений в сосудистой стенке. Также некоторые авторы описывают редукцию утолщения артериальной стенки у женщин в период постменопаузы на фоне длительной заместительной гормонотерапии [18]. Можно сделать предположения, что именно гормональные факторы лежат в основе выраженных изменений длины висцеральных артерий у женщин пожилого возраста.

При изучении особенностей морфометрических параметров брюшной аорты и ее непарных ветвей в группах, систематизированных по значению индекса Пинье, установлено, что 17 из изученных параметров имеют типовые особенности (таблица 2). Установлено, что у мужчин диаметр брюшной аорты на разных уровнях статистически достоверно изменяется в зависимости от типа телосложения. В среднем на уровне чревного ствола, на уровне 5 мм проксимальнее устьев почечных артерий и на уровне 5 мм проксимальнее бифуркации аорты разница между крайними типами (астеническим и гиперстеническим) составляет 2,4 мм. У женщин различия в значении данных показателей колеблются от 2,4 до 3,1 мм. У мужчин наибольший диаметр НБА на $34,3 \%$, а диаметр ВБА на уровне 5 мм дистальнее устья подвздошно-ободочнокишечной артерии на 30,2\% достоверно больше при гиперстеническом типе телосложения по сравнению с астеническим. В то же время разница в значении диаметра левой желудочной артерии между крайними группами составляет 25,8\%, диаметра селезеночной артерии - 16,1\%, а наибольшего диаметра чревного ствола - всего 9,3\%. Наибольший диаметр чревного ствола, а также диаметры левой желудочной и печеночной артерий имеют достоверные различия только между крайними типами телосложения. У женщин типовые различия наибольшего диаметра чревного ствола, селезеночной, общей печеночной артерий, наибольшего диаметра ВБА и НБА не выражены и составляют в среднем 0,5 мм. Диаметр левой желудочной артерии не зависит от типа телосложения.

И у мужчин, и у женщин значения длина брюшного отдела аорты достоверно больше у гиперстеников и составляет $155 \pm 2,2$ и 154,2 $\pm 2,3$ мм соответственно, в то время как у астеников - только 145,9 $\pm 2,9$ и 144,8 $\pm 1,6$ мм соответственно. Таким образом, разница этого показателя между представителями крайних типов телосложения достигает 9,1-9,4 мм. У мужчин длина чревного ствола и основных стволов НБА и ВБА также имеет выраженные типовые особенности. Если значения первых двух параметров достоверно больше у гиперстенического типа, то значения длины основного ствола ВБА в среднем на 5,7 мм больше у астенического типа. У женщин в группе астеников длина чревного ствола равняется 53,2 22,1 мм, в группе

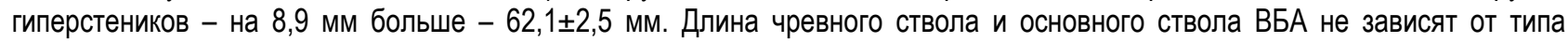
телосложения. Аорто-мезентериальное расстояние у мужчин достоверно различается между нормостениками и астениками на 8,8 мм и между гиперстениками и астениками - на 11,4 мм. У женщин в группе астеников значения данного показателя

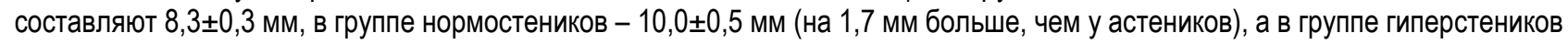
- 16,9 \pm 1 мм (на 8,6 мм больше, чем у астеников).

Степень выраженности изменений угловых параметров в зависимости от типа телосложения варьирует в зависимости от пола. У мужчин угол отхождения чревного ствола в группе нормостеников в среднем на $11,3^{\circ}(38,9 \%)$ больше, чем у астеников, у женщин - на $2,4^{\circ}(7,3 \%)$. Значения угла отхождения чревного ствола у мужчин-гиперстеников на $12,9^{\circ}$ $(44,5 \%)$ больше, чем у астеников, у женщин-гиперстеников - на 16,8\%(51\%). Различия в значениях угла отхождения ВБА между крайними типами телосложения по Пинье достигают у женщин $26,1^{\circ}(78,6 \%)$, у мужчин $-31,3^{\circ}(95 \%)$.

Наличие статистически значимых различий по морфометрическим параметрам брюшной аорты и ее непарных ветвей между конституциональными типами, выделенными с использованием индекса Пинье, вероятнее всего, связано с тем, что в формулу для его расчета входят объемные показатели тела (обхват груди, масса тела). Поэтому его использование в 
качестве фактора группирования выявляет достаточное количество различий сравниваемых параметров, в том числе, зависящих от типа и степени развития абдоминальной жировой клетчатки.

Таблица 2

Морфометрические характеристики брюшной аорты и ее непарных ветвей у мужчин и женщин в зависимости

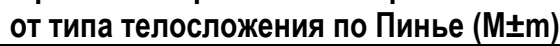

\begin{tabular}{|c|c|c|c|c|}
\hline \multirow{2}{*}{ Морфометрический параметр } & \multirow{2}{*}{ Пол } & \multicolumn{3}{|c|}{ Тип телосложения } \\
\hline & & Астенический & Нормостенический & Гиперстенический \\
\hline \multirow{2}{*}{ Диаметр аорты на уровне чревного ствола, мм } & M & $21,4 \pm 0,9^{2}$ & $23,5 \pm 0,4$ & $23,8 \pm 0,41$ \\
\hline & Ж & $19,8 \pm 0,4^{2}$ & $22,3 \pm 0,4$ & $22,9 \pm 0,3^{1}$ \\
\hline \multirow{2}{*}{$\begin{array}{c}\text { Поперечный диаметр аорты на уровне } 5 \text { мм } \\
\text { проксимальнее устьев почечных артерий (либо } \\
\text { устья проксимальнее расположенной почечной } \\
\text { артерии), мм }\end{array}$} & M & $19,4 \pm 0,9$ & $21,1 \pm 0,4$ & $21,8 \pm 0,3^{1}$ \\
\hline & Ж & $17,4 \pm 0,3^{2}$ & $19,4 \pm 0,4$ & $20,1 \pm 0,3^{1}$ \\
\hline \multirow{2}{*}{$\begin{array}{c}\text { Поперечный диаметр аорты на уровне на уровне } \\
5 \text { мм проксимальнее бифуркации аорты, мм }\end{array}$} & $\mathrm{M}$ & $16,4 \pm 0,8$ & $17,8 \pm 0,3^{3}$ & $18,8 \pm 0,31$ \\
\hline & 世 & $14,3 \pm 0,3^{2}$ & $15,9 \pm 0,2^{3}$ & $16,7 \pm 0,3^{1}$ \\
\hline \multirow{2}{*}{ Длина брюшного отдела аорты, мм } & $\mathrm{M}$ & $145,9 \pm 2,9$ & $152,8 \pm 1,9$ & $155,0 \pm 2,2^{1}$ \\
\hline & Ж & $144,8 \pm 1,6$ & $144,6 \pm 1,7^{3}$ & $154,2 \pm 2,3$ \\
\hline \multirow{2}{*}{ Длина чревного ствола, мм } & $\mathrm{M}$ & $22,4 \pm 1,1^{2}$ & $26,9 \pm 0,9$ & $27,1 \pm 0,7^{1}$ \\
\hline & Ж & $25,3 \pm 0,9$ & $25,2 \pm 0,7$ & $26,5 \pm 0,8$ \\
\hline \multirow{2}{*}{ Наибольший диаметр чревного ствола, мм } & M & $7,5 \pm 0,2^{2}$ & $8,1 \pm 0,2$ & $8,2 \pm 0,2^{1}$ \\
\hline & Ж & $7,1 \pm 0,2^{2}$ & $7,7 \pm 0,1^{3}$ & $7,2 \pm 0,1$ \\
\hline \multirow{2}{*}{ Угол отхождения чревного ствола в градусах } & $\mathrm{M}$ & $29,0 \pm 1,8^{2}$ & $40,3 \pm 2,6$ & $41,9 \pm 2,31$ \\
\hline & Ж & $33 \pm 2,3$ & $35,4 \pm 2,0^{3}$ & $49,8 \pm 2,7^{1}$ \\
\hline \multirow{2}{*}{ Диаметр левой желудочной артерии, мм } & M & $3,1 \pm 0,1^{2}$ & $3,7 \pm 0,1$ & $3,9 \pm 0,11$ \\
\hline & Ж & $3,1 \pm 0,1$ & $3,1 \pm 0,1$ & $3,0 \pm 0,1$ \\
\hline \multirow{2}{*}{ Диаметр селезеночной артерии, мм } & $\mathrm{M}$ & $5,6 \pm 0,2^{2}$ & $6,4 \pm 0,2$ & $6,5 \pm 0,11$ \\
\hline & Ж & $5,9 \pm 0,12$ & $6,4 \pm 0,2$ & $6,2 \pm 0,11$ \\
\hline \multirow{2}{*}{ Диаметр общей печеночной артерии, мм } & $\mathrm{M}$ & $5,6 \pm 0,3$ & $5,5 \pm 0,2$ & $6,0 \pm 0,2$ \\
\hline & Ж & $5,0 \pm 0,2^{2}$ & $5,6 \pm 0,2$ & $5,3 \pm 0,1$ \\
\hline \multirow{2}{*}{$\begin{array}{c}\text { Расстояние между центрами устьев чревного } \\
\text { ствола и верхней брыжеечной артерии, мм }\end{array}$} & $\mathrm{M}$ & $18 \pm 0,5$ & $18,9 \pm 0,4$ & $19,2 \pm 0,4$ \\
\hline & Ж & $17,4 \pm 0,4$ & $17,8 \pm 0,6$ & $17,7 \pm 0,5$ \\
\hline \multirow{2}{*}{ Длина основного ствола ВБА, мм } & $\mathrm{M}$ & $212,9 \pm 3,4^{2}$ & $197,0 \pm 3,1^{3}$ & $207,2 \pm 2,7$ \\
\hline & Ж & $192,0 \pm 3,7$ & $192,2 \pm 3,2$ & $200,0 \pm 4,0$ \\
\hline \multirow{2}{*}{$\begin{array}{c}\text { Наибольший диаметр ВБА (начальные отделы), } \\
\text { мм }\end{array}$} & $\mathrm{M}$ & $7,0 \pm 0,2^{2}$ & $7,7 \pm 0,1^{3}$ & $8,6 \pm 0,2^{1}$ \\
\hline & Ж & $6,5 \pm 0,1$ & $6,8 \pm 0,2$ & $6,8 \pm 0,11$ \\
\hline \multirow{2}{*}{$\begin{array}{c}\text { Диаметр ВБА на уровне } 5 \text { мм дистальнее устья } \\
\text { подвздошно-ободочно-кишечной артерии, мм }\end{array}$} & $\mathrm{M}$ & $4,3 \pm 0,1^{2}$ & $5,0 \pm 0,1^{3}$ & $5,6 \pm 0,11$ \\
\hline & Ж & $3,9 \pm 0,12$ & $4,4 \pm 0,1$ & $4,4 \pm 0,11$ \\
\hline \multirow{2}{*}{ Угол отхождения ВБА в градусах } & $\mathrm{M}$ & $33,0 \pm 3,6^{2}$ & $56,2 \pm 3,1$ & $64,3 \pm 2,71$ \\
\hline & Ж & $33,2 \pm 1,9$ & $38,5 \pm 2,4^{3}$ & $59,3 \pm 2,6^{3}$ \\
\hline \multirow{2}{*}{ Аорто-мезентериальное расстояние, мм } & $\mathrm{M}$ & $8,2 \pm 0,7^{2}$ & $17,0 \pm 1,2$ & $19,6 \pm 1,11$ \\
\hline & Ж & $8,3 \pm 0,4^{2}$ & $10,0 \pm 0,5^{3}$ & $16,9 \pm 1,0^{1}$ \\
\hline \multirow{2}{*}{$\begin{array}{c}\text { Расстояние между центрами устьев верхней } \\
\text { брыжеечной и проксимальнее расположенной } \\
\text { почечной артерии, мм }\end{array}$} & M & $8,4 \pm 1,3$ & $10,3 \pm 1,2$ & $11,4 \pm 0,9$ \\
\hline & Ж & $9,9 \pm 1,2$ & $8,7 \pm 0,8^{3}$ & $11,5 \pm 0,9$ \\
\hline \multirow{2}{*}{$\begin{array}{c}\text { Расстояние между центрами устьев верхней и } \\
\text { нижней брыжеечных артерий, мм }\end{array}$} & $\mathrm{M}$ & $73,8 \pm 3,4$ & $77,6 \pm 1,4$ & $75,1 \pm 1,8$ \\
\hline & 世 & $74,5 \pm 1,5$ & $71,7 \pm 1,2^{3}$ & $76 \pm 1,5$ \\
\hline \multirow{2}{*}{ Длина основного ствола НБА, мм } & $\mathrm{M}$ & $50,2 \pm 2,5^{2}$ & $57,3 \pm 1,8$ & $65,7 \pm 3,91$ \\
\hline & Ж & $53,2 \pm 2,1$ & $54,6 \pm 2,4^{3}$ & $62,1 \pm 2,5^{1}$ \\
\hline \multirow{2}{*}{$\begin{array}{c}\text { Наибольший диаметр НБА (начальные отделы), } \\
\text { мм }\end{array}$} & $\mathrm{M}$ & $3,5 \pm 0,1^{2}$ & $4,4 \pm 0,1^{3}$ & $4,7 \pm 0,11$ \\
\hline & Ж & $3,4 \pm 0,1$ & $3,6 \pm 0,1^{3}$ & $4,1 \pm 0,11$ \\
\hline \multirow{2}{*}{$\begin{array}{c}\text { Расстояние между центрами устьев нижней } \\
\text { брыжеечной и дистальнее расположенной } \\
\text { почечной артерии, мм }\end{array}$} & $\mathrm{M}$ & $63,7 \pm 2,6$ & $63,6 \pm 1,7^{3}$ & $57,1 \pm 1,5^{1}$ \\
\hline & Ж & $58 \pm 1,3$ & $57,4 \pm 1,4$ & $60,1 \pm 1,4$ \\
\hline Расстояние между центром устья нижней & M & $40,2 \pm 2,8$ & $41,2 \pm 1,5$ & $44,3 \pm 1,3$ \\
\hline брыжеечной артерии и бифуркацией аорты, мм & Ж & $38,9 \pm 1,0$ & $40,1 \pm 1,6$ & $42,2 \pm 1,11$ \\
\hline
\end{tabular}

Примечание: ${ }^{1}$ - различия с группой астенического типа; ${ }^{2}-$ различия с группой нормостенического типа; ${ }^{3}-$ различия с группой гиперстенического типа, $\mathrm{p}<0,05$. 
Заключение. Таким образом в результате проведенного исследования установлено, что подавляющее большинство морфометрических параметров брюшной аорты и ее непарных ветвей, измеренных на компьютерных томограммах, имеют выраженные половые, возрастные и типовые особенности. Полученные данные имеют важное клиническое значение, позволяют объективизировать диагностические критерии различных сосудистых синдромов и минимизировать риск проводимых рентгеноэндоваскулярных вмешательств.

\section{ЛИТЕРАTYPA \\ REFERENCES}

1. Gaivoronskiy IV, Kotiv BN, Kovalenko NA, Pelipas' YuV, Bakhovadinova ShB, Amelina ID, Kudryavtseva AD, Dzidzava II, Verbitskiy V. Klinicheskoe znachenie variantnoy anatomii chrevnogo stvola. Vestn. Ross. voen.-med. akad. 2018;1 (61): 235-239.

2. Sapin MR. Anatomiya cheloveka.- Tom 2.- M.: Meditsina,1997.- 560.

3. Semioshko NV. Variantnaya anatomiya vetvleniya chrevnogo stvola i prnilezhashchikh k nemu limfaticheskikh uzlov. Pediatricheskiy vestnik Yuzhnogo Urala. 2015;1:37-42.

4. Sinel'nikov RD, Sinel'nikov YaR. Atlas anatomii cheloveka.- Tom 3.- M.: Meditsina;1996.- 232s.

5. Lubotskiy DN. Osnovy topograficheskoy anatomii.- M.: MEDGIZ, 1953.- 647s.

6. Gangam RR, Lakmala V. A morphometric study of branching pattern of inferior mesenteric artery. Int J Pharm Bio Sci. 2016;7(2):1925.

7. Malnar D, Klasan G, Miletić D, Bajek S, Vranić T, Arbanas J, Bobinac D, Čoklo M. Properties of the Celiac Trunk - Anatomical study. Coll. Antropol. 2010;34(3):917-921.

8. Velikoretskiy AN. Operativnoe lechenie raka podzheludochnoy zhelezy.- M.: Izdanie 1-go Mosk. med. in-ta im. I.M. Sechenova, 1959.- 176s.

9. Sinkeet S, Johnstone M, Maseghe $P$, Saidi M. Branching pattern of inferior mesenteric artery in a black african population: a dissection study. ISRN Anatomy. 2013;2013:1-4.

10. Egorov VI, Yashina NI, Fedorov AV, Vishnevskiy VA, Karmazanovskiy GG, Shevchenko TV. Arterial'nye tseliako-mezenterial'nye aberratsii: sravnenie operatsionnykh dannykh i KT-angiografii. Khirurgiya. Zhurnal im. N.I. Pirogova. 2009;11:4-9.

11. Dandekar UK. Variant anatomy of the celiac trunk: review of literature with a case report. Int J of Biomed and Adv Research. 2014;5(10):480-484.

12. Ognjanovic N. MDCT Angiography of anatomical variations of the celiac trunk and superior mesenteric artery. Arch Biol Sci Belgrade. 2014;66(1):233-240.

13. Markosyan AA. Osnovy morfologii i fiziologii organizma detey i podrostkov.- M.: Meditsina, 1969.- 576s.

14. Barsukov VS, Lobanov AM, Popov VA. Morfometriya aorty v opredelenii vozrasta neopoznannogo umershego. Uchenye zapiski Orlovskogo gosudarstvennogo universiteta: nauchnyy zhurnal. 2012;6(1):198-201.

15. Efimov AA, Kurzin LM, Petrosyan KA. Kolichestvennaya otsenka vozrastnykh izmeneniy morfologicheskikh pokazateley krupnykh arteriy. Vestnik TGU. 2013;18(1):350-352.

16. Zhirnova OA, Beresten' NF, Petrovskaya OR, Bogdanova EYu. Neinvazivnaya diagnostika narusheniya elasticheskikh svoystv arterial'nykh sosudov. Angiologia.ru. 2011;1:27-42.

17. Scuteri A, Lakatta EG, Bos JG, Fleg JL. Effect of estrogen and progestin replacement on arterial stiffness indices in postmenopausal women. Aging clinical and experimental research. 2001;13(2):122-130.

18. Salov IA, Tolstov SM, Karagezyan KM, Rebrov AP. Change of arterial stiffness values in different treatment regimens in menopausal women. Gynecology, Obstetrics and Perinatology. 2018;17(2):25-32.

\section{Авторская справка}

Гайворонский Иван Васильевич, доктор медицинских наук, профессор, заведующий кафедрой, кафедра нормальной анатомии Военно-Медицинской академии им. С.М. Кирова, заведующий кафедрой морфологии Санкт-Петербургского государственного университета, Санкт-Петербург, Россия; e-mail: i.v.gaivoronsky@mail.ru

Быков Петр Михайлович, старший преподаватель, кафедра анатомии и гистологии человека, Белгородский государственный национальный исследовательский университет, Белгород, Россия; e-mail: bpm.aibolit@mail.ru

Гайворонская Мария Георгиевна, доктор медицинских наук, доцент, кафедра морфологии Санкт-Петербургского государственного университета, профессор лечебного факультета Национального медицинского исследовательского центра имени В.А. Алмазова, Санкт-Петербург, Россия; e-mail: solnushko12@mail.ru

Синенченко Георгий Иванович, доктор медицинских наук, профессор, заведующий кафедрой, 2-я кафедра хирургии факультета усовершенствования врачей, Военно-Медицинская академия им. С.М. Кирова, Санкт-Петербург, Россия; е-таil: profsinenchenko@yandex.ru 